\title{
Research on Evaluation and Mechanism of Power Grid Reserve Project Based on Matter Element Model
} \author{
Yuqian Zhang ${ }^{10}$ \\ ${ }^{1}$ Tianjin Tianda Qiushi Electric Power New Technology Co., Ltd. Tianjin, China \\ ${ }^{2}$ State Grid Corporation. Beijing, China \\ ${ }^{3}$ State Grid Beijing Electric Power Company. Beijing, China \\ ${ }^{4}$ Tianjin Tianda Qiushi Electric Power New Technology Co., Ltd. Tianjin, China \\ ${ }^{5}$ Tianjin Tianda Qiushi Electric Power New Technology Co., Ltd. Tianjin, China \\ ${ }^{6}$ Tianjin Tianda Qiushi Electric Power New Technology Co., Ltd. Tianjin, China \\ ${ }^{7}$ Tianjin Tianda Qiushi Electric Power New Technology Co., Ltd. Tianjin, China \\ ${ }^{8}$ Tianjin Tianda Qiushi Electric Power New Technology Co., Ltd. Tianjin, China \\ ${ }^{9}$ Tianjin Tianda Qiushi Electric Power New Technology Co., Ltd. Tianjin, China \\ ${ }^{10}$ Tianjin Tianda Qiushi Electric Power New Technology Co., Ltd. Tianjin, China
}

Jun Yan ${ }^{1}$, Yuheng Sha',*, Tiezheng Wang ${ }^{3}$, Yanlai Zhang ${ }^{4}$, Ziwei Zhu ${ }^{5}$, Wenlong $\mathrm{Li}^{6}$, Yannan Guo ${ }^{7}$, Wenqi Li ${ }^{8}$, Jing Zhang ${ }^{9}$,

\begin{abstract}
In view of the increasing number of power grid reserve projects, how to reasonably evaluate power grid reserve projects and formulate power grid reserve project management mechanisms is of great significance for improving project management levels, optimizing resource allocation, and realizing the sustainable development of power grid enterprises. This paper proposes an evaluation method for power grid reserve projects based on the matter-element model. First, considering the influence factors of technology, economy, environment, etc., this paper constructs an evaluation index system for reserve projects considering policy, safety, and benefits; The method of weighting determines the index weight, and evaluates the project in combination with the matter-element model, laying a foundation for the research of the project reserve mechanism, and finally uses examples to verify the effectiveness of the method.
\end{abstract}

\section{Introduction}

The power grid development task is heavy, the investment scale is large, and the investment projects are many. As the entrance to project management, project reserve is an important foundation and basis for project management. Only by controlling the entrance, the follow-up project management and fund management can really be put in place [1]. Strengthening project reserve management, adhering to the best choice, and ensuring that limited resources are used for the most urgently needed projects are not only to meet the current needs of the current macroeconomic and power sales growth rate, to improve the company's operating efficiency, but also to adapt to the reform of the power system to ensure projects It meets the requirements of investment supervision, is included in the scope of valid asset identification and obtains the preconditions for investment returns [2].

With the operation of the project reserve library, power grid companies need to put forward more specific project evaluation standards based on their own conditions, reasonably select evaluation indicators and weighting methods, improve the accuracy of project evaluation, and make the evaluation results of reserve projects more accurate and reasonable [3]. Literature [4] puts forward five evaluation indicators of power supply quality, equipment technical level, grid structure, load supply capacity, and economic benefits, and they are used as the first-level indicators for planning project evaluation. Literature [5] puts forward an evaluation index system in four aspects: load growth, perfect grid, safe power supply and voltage quality to evaluate distribution network projects. Literature [6] proposed a comprehensive evaluation index system for the adaptability of distribution network planning and construction in three aspects: power supply capacity, equipment technology level, and grid scale. Literature [7] puts forward an economic index system for power grid planning in five aspects: comprehensive cost, economic benefit, reliability benefit, social benefit, and environmental benefit. Literature [8] proposes an evaluation index system for safety effectiveness cost in three aspects: safety, effectiveness, and cost. These documents provide a reference for the storage of power grid reserve projects, but there are many factors involved in power grid projects, and the arrangement of projects needs to be considered from multiple perspectives such as policy, safety and efficiency. It is urgent to establish an objective and comprehensive evaluation index system for power grid reserve projects.

In response to the above problems, this article first analyzes the influencing factors of the storage of reserve

${ }^{*}$ Corresponding author: Yuhengsha@126.com 
projects, and on this basis, constructs a comprehensive project evaluation index system from three aspects of policy, safety and efficiency, and establishes a project evaluation system to realize the Comprehensive evaluation provides a basis for improving the management level of power grid projects, and has guiding significance for improving the level of intensive and lean management of project investment, reducing investment risks of various power grid projects, and maximizing power grid benefits.

\section{Comprehensive evaluation of reserve projects}

\subsection{Factors affecting the storage of reserve items}

In terms of policies, the new situation of power system reform and the new stage of power grid development, the construction of power grid projects requires multiple considerations, such as supporting high-quality economic development, promoting energy transformation, ensuring power supply security, and enhancing the competitiveness of the state-owned economy; at the same time, investment by central enterprises With continuous strengthening of supervision and stricter supervision and review of transmission and distribution pricing costs, power grid operation assessment is facing new challenges. Project arrangements should fully consider national policy requirements and prioritize projects that are in line with the company's long-term interests and are conducive to the sustainable development of the company.

In terms of power grid security, in the traditional sense, the power grid mainly maintains the stable operation of the power system. On this basis, the main factors that must be paid attention to are the average power outage time of each household. In the context of the new electricity reform, it is necessary to pay more attention to user needs and improve user satisfaction with services. However, as the electricity market reform encourages social capital to invest in the distribution and sale of electricity, the increase of market entities not only increases the uncertainty of the grid operation mode and the flow direction of the power grid, but also brings challenges to the safe operation of the grid. Therefore, the stable operation of the grid is ensured and based on user demand. The high-quality service satisfaction rate has become an important factor that power grids must pay attention to under the new situation.

On the basis of meeting the needs of power grid development, and fully considering the input and output benefits of the project, the investment benefits of the grid company are first of all obvious economic benefits, which are manifested in the power efficiency and power supply cost benefits, mainly by improving the power supply capacity and optimization of the power grid Grid structure, reduction of line loss and other measures to achieve. The second is the hidden social benefit, which is reflected in effectively meeting the local demand for effective load growth, meeting the safety of power supply, and providing a guarantee for the rapid and sound development of the local economy. It has also improved regional production and electricity consumption and promoted faster regional economic development. Social benefits are often intangible and cannot be accurately measured in currency, but these intangible social benefits are huge. Therefore, reserve projects need to be evaluated from the perspective of benefits. For projects with good benefits, the warehousing sequence should be advanced to increase investment. Standard of accuracy.

\subsection{Comprehensive evaluation index system for reserve projects}

Considering the influencing factors of the storage of reserve projects, the difficulty of index acquisition and quantification, three primary indicators including policy, safety, and benefit are comprehensively selected, and multiple secondary indicators under the primary indicators are shown in Table 1.

Table1. Comprehensive evaluation index system for reserve projects

\begin{tabular}{|c|c|}
\hline First level indicators & Second level indicators \\
\hline Policy indicator $\left(\mathrm{A}_{1}\right)$ & Policy adaptability $\left(\mathrm{B}_{11}\right)$ \\
\hline \multirow{3}{*}{ Safety indicators $\left(\mathrm{A}_{2}\right)$} & "N-1" resolution rate $\left(\mathrm{B}_{21}\right)$ \\
\hline & $\begin{array}{l}\text { Overload resolution rate } \\
\qquad\left(\mathrm{B}_{22}\right)\end{array}$ \\
\hline & $\begin{array}{c}\text { Standard net frame lifting } \\
\text { rate }\left(\mathrm{B}_{23}\right)\end{array}$ \\
\hline \multirow{3}{*}{ Benefit indicators $\left(\mathrm{A}_{3}\right)$} & $\begin{array}{c}\text { Reduce comprehensive line } \\
\text { loss rate }\left(\mathrm{B}_{31}\right)\end{array}$ \\
\hline & $\begin{array}{c}\text { Unit investment increase } \\
\text { supply load }\left(\mathrm{B}_{32}\right)\end{array}$ \\
\hline & $\begin{array}{c}\text { Unit investment increase } \\
\text { power supply }\left(\mathrm{B}_{33}\right)\end{array}$ \\
\hline
\end{tabular}

\section{Subjective and objective combination weighting based on AHP-entropy weight method}

AHP [9] adopts the method of subjective value, quantitatively compares qualitative indicators, and obtains indicator weights to make decisions. Among them, the value is subjectively influenced by people and has a greater impact on the weight; in order to reduce the influence of subjective factors, the entropy weight method is introduced. Objective weights, combining AHP method and entropy weight method to obtain subjective and objective combined weights.

\subsection{Subjective empowerment based on AHP}

The main idea of AHP is to combine qualitative and quantitative methods to decompose the multi-objective, multi-criteria, and difficult-to-quantify complex system decision-making problem into multi-level single-objective problems. According to the interrelated influence and affiliation between the indicators, the indicators are aggregated and combined at different levels to form a multi-level analysis structure model, so that the problem is ultimately reduced to the lowest level (plans, measures, etc. for decision-making) relative to the highest level The determination of the relative importance of the (general 
goal) or the arrangement of the relative order of superiority and inferiority [10].

The steps of analytic hierarchy process can be divided into four steps:

(1) Hierarchical structure model;

(2) Construct a judgment matrix;

(3) Level list sorting and consistency check;

(4) Weight calculation.

AHP weight calculation methods include geometric average method, arithmetic average method, eigenvector method and least square method. This paper uses the eigenvector method to calculate the eigenvalues and eigenvectors of the judgment matrix, that is, calculate the eigenvalues and eigenvectors of the judgment matrix that satisfy the following relationships:

$$
A V=\lambda_{\max } V
$$

In the formula, $\lambda_{\max }$ is the maximum eigenvalue of the judgment matrix $\mathrm{A}, \mathrm{V}$ is the eigenvector corresponding to $\lambda_{\max }$, and the weight value is the weight vector normalized by $\mathrm{V}$.

\subsection{Objective weighting based on entropy method}

Entropy weight method is an objective weighting method. In the specific use process, the entropy weight method uses information entropy to calculate the entropy weight of each indicator according to the degree of variation of each indicator, and then corrects the weight of each indicator through entropy weight. Thus, a more objective indicator weight can be obtained. The improved entropy method is based on the entropy method, using standardized transformation and coordinate translation methods to improve the entropy weight method [11].

Suppose the subjective weight vector is $v_{j}$, the objective weight vector is $w_{j}$, and the combined weight is $r_{j}$. According to the principle of minimum discriminative information, the combination weights $r_{j}(i), v_{j}(i)$ and $w_{j}(i)$ are as close as possible to obtain the combination weight formula:

$$
\begin{gathered}
r_{j}=\frac{\sqrt{v_{j}(i) w_{j}(i)}}{\sum_{j=1}^{m} \sqrt{v_{j}(i) w_{j}(i)}} \\
\sum_{i=1}^{m} r(i)=1 ; \quad r(i)>0
\end{gathered}
$$

\section{Matter element analysis method modeling process}

Matter element analysis is a theory that studies the laws and methods of finding ideas and finding solutions when solving incompatible problems [12].
(1) Determine the matter element formed by the classical domain, the node domain and the object to be recognized.

(2) The weight is determined by the combination of subjective and objective.

(3) Establish the correlation function and calculate the correlation function value.

(4) Relevance and rating.

\subsection{Basic concepts of matter element analysis}

A multi-level matter-element model is constructed according to the comprehensive evaluation index of the reserve project. The matter element is described by $R=(N, C, V)$. Given a thing $\mathrm{N}$, the value $\mathrm{v}$ of the characteristic $\mathrm{C}$ of the thing. When the thing $\mathrm{N}$ with $\mathrm{n}$ evaluation indexes $\mathrm{c}, \quad c_{1}, c_{2}, \cdots, c_{n}$ and its corresponding value $v_{1}, v_{2}, \cdots, v_{n}$, the comprehensive evaluation index matter-element model of the reserve project is [12]:

$$
R=\left[\begin{array}{ccc}
N & c_{1} & v_{1} \\
& c_{2} & v_{2} \\
& \cdots & \cdots \\
& c_{n} & v_{n}
\end{array}\right]=\left[\begin{array}{l}
R_{1} \\
R_{2} \\
\cdots \\
R_{n}
\end{array}\right]
$$

In the formula, $\mathrm{R}$ is an $\mathrm{n}$-dimensional matter element, denoted by $R=(N, C, V)$

Among them, $C=\left(\begin{array}{c}c_{1} \\ c_{2} \\ \vdots \\ c_{n}\end{array}\right), \quad V=\left(\begin{array}{c}v_{1} \\ v_{2} \\ \vdots \\ v_{n}\end{array}\right)$, The matter element of $\mathrm{R}$ is $R_{i}=\left(N, C_{i}, V_{i}\right), \quad(i=1,2, \ldots, n)$

\subsection{Classical field and nodal field matter element matrix}

Matter element matrix:

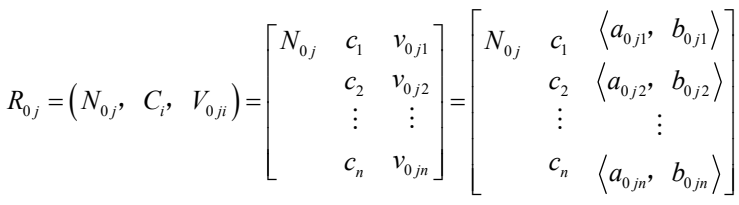

In the formula, $N_{0 j}$ represents the standard thing; $c_{i}$ represents the characteristic of $N_{0 j} ; v_{0 j i}=\left\langle a_{0 j i}, b_{0 j i}\right\rangle$, $v_{0 j i}$ represents the range of value specified by $N_{0 j}$ to $c_{i}$.

Nodal matter element matrix: 


$$
R_{p}=\left(N_{P}, \quad C_{P}, V_{P}\right)=\left[\begin{array}{ccc}
N_{P} & c_{1} & v_{p 1} \\
& c_{2} & v_{p 2} \\
& \vdots & \vdots \\
& c_{n} & v_{p n}
\end{array}\right]=\left[\begin{array}{ccc}
N_{P} & c_{1} & \left\langle a_{p 1}, b_{p 1}\right\rangle \\
& c_{2} & \left\langle a_{p 2}, b_{p 2}\right\rangle \\
& \vdots & \vdots \\
& c_{n} & \left\langle a_{p n}, b_{p n}\right\rangle
\end{array}\right](6)
$$

In the formula, $N_{P}$ represents the section domain object, and $v_{p i}=\left\langle a_{p i}, b_{p i}\right\rangle$ represents the range of the value taken by $N_{p}$ to $c_{i}$.

\subsection{Determine the weight of each indicator}

For the comprehensive evaluation of the project, the subjective and objective combination weighting method of AHP-entropy weight method is used to determine the weight of each indicator $\lambda_{i}$.

\subsection{Relevance calculation}

The establishment of the correlation function quantifies the process of solving contradictory problems. Its value range is the entire real number axis, and the correlation function is:

$$
\begin{gathered}
k_{i}\left(v_{i}\right)=\left\{\begin{array}{c}
\frac{\rho\left(v_{i}, X_{0 i}\right)}{\rho\left(v_{i}, X_{p i}\right)-\rho\left(v_{i}, X_{0 i}\right)}, v_{i} \notin X_{0 i} \\
\frac{-\rho\left(v_{i}, X_{0 i}\right)}{\left|X_{0 i}\right|}, v_{i} \in X_{0 i}
\end{array}\right. \\
\rho\left(v_{i}, X_{0 i}\right)=\left|v_{i}-\frac{1}{2}\left(a_{0 i}+b_{0 i}\right)\right|-\frac{1}{2}\left(b_{0 i}-a_{0 i}\right),(i=1,2, \ldots, n)
\end{gathered}
$$

According to the above correlation degree calculation, the obtained correlation degrees are multiplied by the combination weight $\lambda_{i}$ of the AHP-entropy weight method to obtain the comprehensive correlation degree value $K_{j}(P)$ of each index:

$$
K_{j}(P)=\sum_{i=1}^{n} \lambda_{i} K_{j}\left(v_{i}\right)
$$

In the formula, $K_{j}(P)$ is the comprehensive correlation degree of each level $\mathrm{j} ; K_{j}\left(v_{i}\right)$ is the relationship degree of each level; $\lambda_{i}$ is the weight of each evaluation index.

$$
K_{j 0}=\max \left(k_{j}(P)\right),(j=1,2, \cdots, n)
$$

Then the evaluation thing $\mathrm{P}$ belongs to grade $j 0$.

\section{Case analysis}

\subsection{Select certain engineering data}

This paper selects a new construction project of $10 \mathrm{kV}$ Shawan 001 line in a certain city as an example, and uses the above-mentioned method for comprehensive project evaluation.

Table2. List of candidate project indicators

\begin{tabular}{|c|c|c|c|c|c|c|c|}
\hline project name & $\mathbf{B}_{11}$ & $\mathbf{B}_{21}$ & $\mathbf{B}_{22}$ & $\mathbf{B}_{\mathbf{2 3}}$ & $\mathbf{B}_{\mathbf{3 1}}$ & $\mathbf{B}_{\mathbf{3 2}}$ & $\mathbf{B}_{\mathbf{3 3}}$ \\
\hline $\begin{array}{c}\text { New construction of } \\
\text { Shawan 001 line }\end{array}$ & 100 & 50 & 15 & 20 & 4.99 & 0.004 & 0.02 \\
\hline
\end{tabular}

\subsection{Classical field, nodal field matter element matrix}

According to the candidate project data, the project warehousing principles are divided into four levels: excellent, good, acceptable, and poor. The value range of each level is shown in Table 3.

Table3. List of candidate project indicators

\begin{tabular}{|c|c|c|c|c|c|c|c|}
\hline Indicators & $\mathrm{B}_{11}$ & $\mathrm{~B}_{21}$ & $\mathrm{~B}_{22}$ & $\mathrm{~B}_{23}$ & $\mathrm{~B}_{31}$ & $\mathrm{~B}_{32}$ & $\mathrm{~B}_{33}$ \\
\hline $\mathrm{A}$ & $100 \sim 75$ & $100 \sim 75$ & $100 \sim 75$ & $100 \sim 75$ & $8 \sim 6$ & $0.004 \sim 0.003$ & $0.04 \sim 0.03$ \\
\hline $\mathrm{B}$ & $75 \sim 50$ & $75 \sim 50$ & $75 \sim 50$ & $75 \sim 50$ & $6 \sim 4$ & $0.003 \sim 0.002$ & $0.03 \sim 0.02$ \\
\hline $\mathrm{C}$ & $50 \sim 25$ & $50 \sim 25$ & $50 \sim 25$ & $50 \sim 25$ & $4 \sim 2$ & $0.002 \sim 0.001$ & $0.02 \sim 0.01$ \\
\hline $\mathrm{D}$ & $25 \sim 0$ & $25 \sim 0$ & $25 \sim 0$ & $25 \sim 0$ & $2 \sim 0$ & $0.001 \sim 0.00$ & $0.01 \sim 0.0$ \\
\hline
\end{tabular}

In the comprehensive evaluation of the reserve projects, the larger the value, the more optional the project is. The maximum value is used for the standard normalization of the project evaluation, as shown in Table 4.

Table4. Normalization and Standard Division of Comprehensive Evaluation Indexes of Reserve Projects

\begin{tabular}{|c|c|c|c|c|c|c|c|}
\hline Indicators & $\mathrm{B}_{11}$ & $\mathrm{~B}_{21}$ & $\mathrm{~B}_{22}$ & $\mathrm{~B}_{23}$ & $\mathrm{~B}_{31}$ & $\mathrm{~B}_{32}$ & $\mathrm{~B}_{33}$ \\
\hline $\mathrm{A}$ & $1.00 \sim 0.75$ & $1.00 \sim 0.75$ & $1.00 \sim 0.75$ & $1.00 \sim 0.75$ & $1.00 \sim 0.75$ & $1.00 \sim 0.75$ & $1.00 \sim 0.75$ \\
\hline $\mathrm{B}$ & $0.75 \sim 0.50$ & $0.75 \sim 0.50$ & $0.75 \sim 0.50$ & $0.75 \sim 0.50$ & $0.75 \sim 0.50$ & $0.75 \sim 0.500 .75 \sim 0.50$ \\
\hline $\mathrm{C}$ & $0.50 \sim 0.25$ & $0.50 \sim 0.25$ & $0.50 \sim 0.25$ & $0.50 \sim 0.25$ & $0.50 \sim 0.25$ & $0.50 \sim 0.25$ & $0.50 \sim 0.25$ \\
\hline $\mathrm{D}$ & $0.25 \sim 0$ & $0.25 \sim 0$ & $0.25 \sim 0$ & $0.25 \sim 0$ & $0.25 \sim 0$ & $0.25 \sim 0$ & $0.25 \sim 0$ \\
\hline
\end{tabular}

\subsection{Determine the weight}

According to the scale given by the experts, the judgment matrix is established, and the average value of the weight is obtained as the subjective weight value of the evaluation, as shown in Table 5.

Table5. Subjective weight of comprehensive evaluation index for reserve projects

\begin{tabular}{|c|c|c|c|c|}
\hline $\begin{array}{c}\text { First level } \\
\text { indicators }\end{array}$ & Weight & $\begin{array}{c}\text { Second level } \\
\text { indicators }\end{array}$ & Weight & $\begin{array}{c}\text { Comprehens } \\
\text { ive weight }\end{array}$ \\
\hline $\begin{array}{c}\text { Policy indicator } \\
\left(\mathrm{A}_{1}\right)\end{array}$ & 0.50 & $\begin{array}{c}\text { Policy adaptability } \\
(\mathrm{B} 11)\end{array}$ & 1.00 & 0.50 \\
\hline $\begin{array}{c}\text { Safety indicators } \\
\left(\mathrm{A}_{2}\right)\end{array}$ & 0.30 & $\begin{array}{c}\mathrm{N}-1 " \text { resolution } \\
\text { rate }(\mathrm{B} 21)\end{array}$ & 0.21 & 0.06 \\
\hline
\end{tabular}




\begin{tabular}{|c|c|c|c|c|}
\hline $\begin{array}{c}\text { First level } \\
\text { indicators }\end{array}$ & Weight & $\begin{array}{c}\text { Second level } \\
\text { indicators }\end{array}$ & Weight & $\begin{array}{c}\text { Comprehens } \\
\text { ive weight }\end{array}$ \\
\hline \multirow{5}{*}{$\begin{array}{c}\text { Overload } \\
\text { resolution rate } \\
\text { (B22) }\end{array}$} & 0.61 & 0.18 \\
\hline \multirow{2}{*}{$\begin{array}{c}\text { Standard net frame } \\
\text { lifting rate (B23) }\end{array}$} & 0.18 & 0.05 \\
\hline \multirow{2}{*}{$\left(\mathrm{A}_{3}\right)$} & 0.20 & $\begin{array}{c}\text { Reduce } \\
\text { comprehensive line } \\
\text { loss rate (B31) }\end{array}$ & 0.26 & 0.05 \\
\cline { 2 - 5 } & $\begin{array}{c}\text { Unit investment } \\
\text { increase supply } \\
\text { load (B32) }\end{array}$ & 0.55 & 0.11 \\
\cline { 2 - 5 } & $\begin{array}{c}\text { Unit investment } \\
\text { increase power } \\
\text { supply (B33) }\end{array}$ & 0.19 & 0.04 \\
\hline
\end{tabular}

Use the entropy method to calculate the objective weight of the comprehensive evaluation of the reserve project, as shown in Table 6.

Table6. Objective weight of comprehensive evaluation index for reserve projects

\begin{tabular}{|c|c|c|c|c|c|c|c|}
\hline Indicators & $\mathrm{B}_{11}$ & $\mathrm{~B}_{21}$ & $\mathrm{~B}_{22}$ & $\mathrm{~B}_{23}$ & $\mathrm{~B}_{31}$ & $\mathrm{~B}_{32}$ & $\mathrm{~B}_{33}$ \\
\hline $\begin{array}{c}\text { Weight } \\
\text { coefficient }\end{array}$ & 0.06 & 0.13 & 0.09 & 0.09 & 0.05 & 0.45 & 0.13 \\
\hline
\end{tabular}

The combination weight is calculated according to the AHP-entropy weight method, and the results are shown in Table 7.

Table7. Comprehensive weight of comprehensive evaluation index for reserve projects

\begin{tabular}{|c|c|c|c|c|c|c|c|}
\hline $\begin{array}{c}\text { Indicator } \\
\mathbf{s}\end{array}$ & $\mathrm{B}_{11}$ & $\mathrm{~B}_{21}$ & $\mathrm{~B}_{22}$ & $\mathrm{~B}_{23}$ & $\mathrm{~B}_{31}$ & $\mathrm{~B}_{32}$ & $\mathrm{~B}_{33}$ \\
\hline Weight & 0.21 & 0.11 & 0.16 & 0.09 & 0.06 & 0.28 & 0.09 \\
\hline
\end{tabular}

\subsection{Matter element analysis correlation calculation}

The index data of the project to be evaluated is normalized, as shown in Table 8.

Table8. Normalized value of project indicator data

\begin{tabular}{|c|c|c|c|c|c|c|c|}
\hline project name & $\mathbf{B}_{11}$ & $\mathbf{B}_{21}$ & $\mathbf{B}_{22}$ & $\mathbf{B}_{23}$ & $\mathbf{B}_{31}$ & $\mathbf{B}_{32}$ & $\mathbf{B}_{33}$ \\
\hline $\begin{array}{c}\text { New construction of } \\
\text { Shawan 001 line }\end{array}$ & 1.00 & 0.50 & 0.15 & 0.20 & 0.05 & 1.00 & 0.50 \\
\hline
\end{tabular}

According to the above-mentioned matter-element analysis correlation degree calculation, combined with the combination weighting of the AHP-entropy weight method, the comprehensive evaluation results of the project are obtained, as shown in Table 9.

Table9. Comprehensive evaluation results of reserve projects

\begin{tabular}{|c|c|c|c|c|}
\hline Indicators & $\mathrm{A}$ & $\mathrm{B}$ & $\mathrm{C}$ & $\mathrm{D}$ \\
\hline Project & -0.88826 & 0.02316 & -1.24811 & -1.62234 \\
\hline
\end{tabular}

From the above calculation results, it can be seen that the project is in a good state of warehousing and can be entered into the project library as meeting policy, safety, and environment. Among them, the project has a higher possibility of storage in meeting the policy and unit investment increase in supply load, and the evaluation result of the project is consistent with the actual entry of the project.

\section{Research on Reserve Mechanism of Power Grid Project}

Based on the analysis of the above-mentioned project reserves, the following three mechanisms are summarized, which have certain reference and guiding significance for power grid enterprises to carry out project reserve work.

(1) Construct a sound project generation mechanism

Combined with grid investment and actual operation, this manual summarizes the investment-oriented label. For various power grid projects, clear basic specifications should be formulated to ensure the smooth flow of project generation and improve work efficiency. At the same time, with the feedback optimization in the dynamic management process, the project generation mechanism needs to be continuously improved.

(2) Realize a dynamic project reserve management mechanism

The project reserve is a process of dynamic update, and the project reserve library is dynamically updated as new projects are put in and the reserve projects are released each year. Therefore, it is necessary to formulate corresponding management procedures based on the dynamic flow of the project reserve. It should also be noted that with the feedback optimization in the linkage management process, the project reserve management mechanism should be able to achieve dynamic adjustments.

(3) Form a standard reserve project evaluation mechanism

The evaluation of grid reserve projects is the core work of the entire reserve project storage process, and only accurate and effective evaluation results can provide valuable feedback information for the management of the reserve. Therefore, the multi-dimensional project reserve integrated evaluation model based on the matter-element model forms a standardized grid reserve project evaluation mechanism that not only satisfies the standardized management of grid construction, but also realizes efficient and scientific management processes.

\section{Conclusion}

This paper analyzes the influencing factors of distribution network projects, builds a comprehensive project evaluation system based on policies, safety, and benefits, uses matter-element analysis to establish project warehousing ratings, and uses AHP-entropy method to calculate the main - objective weight and the correlation degree of the matter element analysis method obtain the comprehensive correlation degree, and the comprehensive evaluation of the reserve project is carried out to provide 
the basis for the storage of the reserve project. Finally, the reserve mechanism of power grid projects is summarized, which provides a certain reference significance for power grid companies to make decisions on project reserves.

\section{Acknowledgment}

This work was supported by the 2020 Science and Technology Project of the State Grid Corporation of China. Project name: Research on Intelligent Management and Control Technology and Application of Data-Driven Power Grid Enterprise Project, Project no. JSB17202000260.

the State Grid Corporation of China, Project no. JSB17202000260.

\section{References}

1. Z Long, "The important significance and working ideas of the preparation of project reserve planning," China Engineering Consulting, vol.240, pp. 7883,2020 .

2. H Lidong, L Mingkai, J Bowen, J Nian, B Yu, "Research and application of distribution network optimization system based on multiple attribute decision making," Shaanxi electric power, vol.45, pp.61-65,2017.

3. F Gaoshan, Z Xunjing, Z Zhuan, "Reserve database evaluation of distribution network projects based on multi attribute decision making," Power System and Clean Energy, vol.36, pp.26-30, January 2020.

4. Z Juan, Y Yang, H Changzhan C Kai, "The Comprehensive Evaluation Model of the Schedule of the Power Grid Reserve Project," Shandong electric power, vol.45, pp.37-41, November 2018.

5. Z Lei, G Qinjin, P Dan, G Yancheng, C Yuren , Z Jincheng, "Evaluation index system of distribution power project," Power System and Clean Energy,vol.30, pp.19-23, June 2014.

6. Y Feng, Z Haiyan, "Benefit analysis of distribution network planning based on improved entropyweighted," Power System and Clean Energy, vol.34, pp.7-11, June 2018.

7. L Hengwei, Study on the method of combination optimal selection and comprehensive evaluation of power network planning projects, Huazhong University of Science \& Technology,2019.

8. C Liangyu, A comparison and decision system of power grid planning based on SEC, Huazhong University of Science \& Technology,2019.

9. W Lianfen, X shubo, Introduction to AHP, China Renmin University Press, 1990.

10. G Jinyu, Z Zhongbin, S Qingyun, "Study and applications of analytic hierarchy process," China Safety Science Journal, vol.18, pp.148-153, May 2008.

11. C Huazhen, L Dong, H Fenglu, "Comprehensive evaluation of equipment utilization of distribution network based on improved entropy-weighted," Electromechanical Engineering Technology, vol.45, pp.108-113, January 2016.

12. Y Yuxin, Z Xunfeng, "Evaluation of Investment Risk of Power Grid Construction Project Based on Matter Element Analysis," China Electric Power Education,pp.168-169,2007. 